\title{
Resolution of critical haemodynamic instability with urgent decompressive mini-laparotomy for abdominal compartment syndrome - a case report
}

\author{
Trent Hartshorne*1, Barry Dixon' and Rodney J Woods ${ }^{2}$
}

Abdominal compartment syndrome, a relatively recently identified disorder [1,2], is traditionally managed in theatre with a semi-elective surgical decompressive laparotomy leaving the abdomen open [3]. Fewer options exist, however, in patients who develop critical haemodynamic instability in the ICU.

We describe the case of a 58-year-old woman admitted to the ICU with hypotension and abdominal distension. She had been discharged from the ICU 48 hours earlier after a prolonged admission with complications of a caecal perforation including ischaemic small bowel, fungal bloodstream infection and renal failure. On readmission to the ICU her abdomen was significantly distended without bowel sounds. Her haemoglobin was $88 \mathrm{~g} / \mathrm{l}$ and lactate was $4.1 \mathrm{mmol} / \mathrm{l}$. The patient was intubated, commenced on low-dose noradrenaline and taken for an abdominal computed tomography scan with oral contrast, which showed a large intraperitoneal fluid collection (Figure 1).

A pigtail catheter was inserted into her left flank, but $<100 \mathrm{ml}$ clear fluid could be drained. Critical haemodynamic instability soon developed, with her mean arterial blood pressure falling to $35 \mathrm{mmHg}$, despite escalating the noradrenaline infusion to $70 \mu \mathrm{g} /$ minute, repeated adrenaline boluses of between 100 and $500 \mu \mathrm{g}(2 \mathrm{~g}$ total), and additional fluid resuscitation via the central access. Given the dire situation, after urgent consultation and instruction from the surgeon (who was not in the hospital) by telephone, an immediate bedside mini-laparotomy was performed to decompress her abdomen. This was performed by the ICU registrar who had no formal surgical training. A left-sided 7-cm lateral scalpel incision

*Correspondence: trent.hartshorne@svhm.org.au

'Department of Intensive Care, St Vincent's Hospital, PO Box 2900, Fitzroy, VIC 3065, Australia

Full list of author information is available at the end of the article

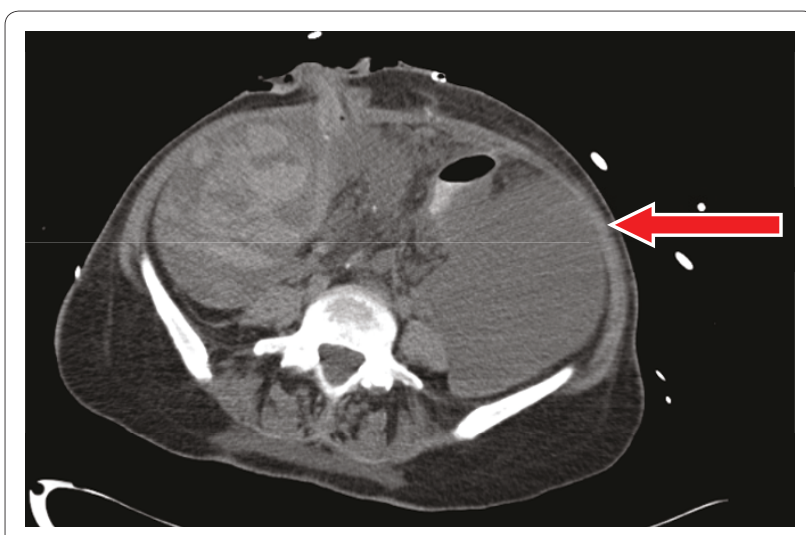

Figure 1. Abdominal computed tomography scan demonstrating intraperitoneal free fluid. Arrow indicates site of mini-laparotomy.

was made parallel to the midline laparotomy, through the abdominal layers of skin, scarpa's fascia, muscle and peritoneum. Care was taken not to damage with abdominal viscera by making the incision away from the patient's stoma site and digital insertion through the peritoneal layer. After the peritoneum was opened, vigorous abdominal compressions were performed evacuating approximately 31 of straw-coloured fluid. The patient's abdomen became less tense, her circulation improved and she was weaned off noradrenaline over the next 20 minutes. The incision was covered with a stoma bag (Figure 2) and a further $1.75 \mathrm{l}$ were drained.

We describe a patient with abdominal compartment syndrome, secondary to tense ascites, which was a key factor resulting in the development of critical haemodynamic instability. An urgent decompressive minilaparotomy resulted in resolution of the patient's haemodynamic instability. We wish to highlight that abdominal compartment syndrome is a reversible factor that can be corrected to prevent cardiac arrest. 


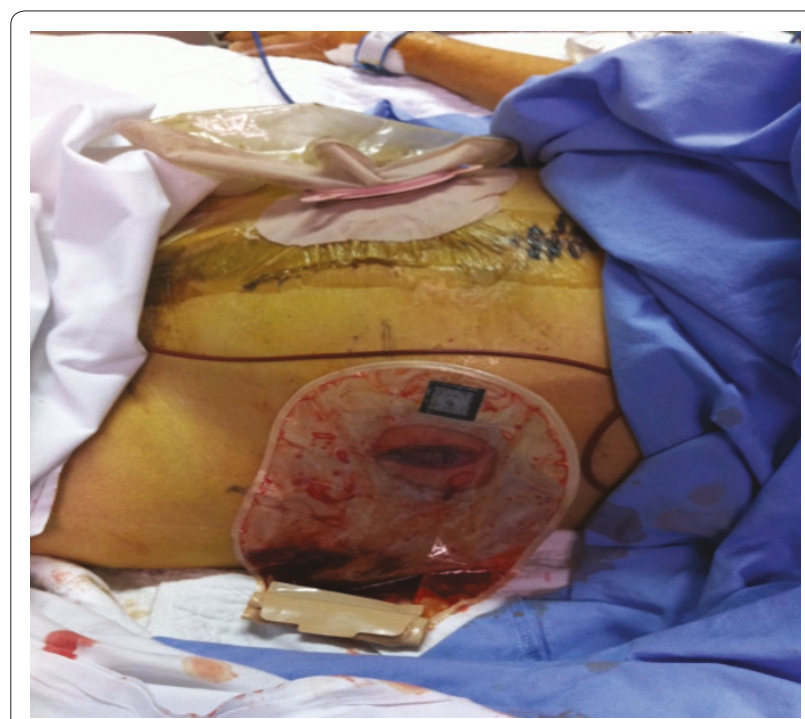

Figure 2. Site of mini-laparotomy over the left flank.

\section{Competing interests}

The authors declare that they have no competing interests.

\section{Acknowledgements}

Written consent to publish was received from the patient's next of kin.

\section{Authors' contributions}

$\mathrm{TH}, \mathrm{BD}$ and RJW were involved in patient management. TH and BD drafted the initial report. All authors read and approved the final manuscript.

\section{Authors' details}

'Department of Intensive Care, St Vincent's Hospital, PO Box 2900, Fitzroy, VIC 3065, Australia. 2Department of Surgery, St Vincent's Hospital, PO Box 2900,

Fitzroy, VIC 3065, Australia.

Published: 2 November 2012

\section{References}

1. Cullen DJ, Coyle JP, Teplick R, Long MC: Cardiovascular, pulmonary and renal effects of massively increased intra-abdominal pressure in critically ill patients. Crit Care Med 1989, 17:1 18-121.

2. Schein M, Wittmann DH, Aprahamian CC, Condon RE: The abdominal compartment syndrome: the physiological and clinical consequences of elevated intra-abdominal pressure. J Am Coll Surg 1995, 180:745-753.

3. Ivatury RR, Kolkman KA, Johansson K: Management of the open abdomen. Acta Clin Belg Supp/ 2007, Suppl 1:206-212.

doi:10.1186/cc11655

Cite this article as: Hartshorne T, et al.: Resolution of critical haemodynamic instability with urgent decompressive mini-laparotomy for abdominal compartment syndrome - a case report. Critical Care 2012, 16:452. 